\title{
Geostatistical modelling of air temperature in a mountainous region of Northern Spain
}

\author{
Raquel Benavides ${ }^{\mathrm{a}, *}$, Fernando Montes ${ }^{\mathrm{b}}$, Agustín Rubio ${ }^{\mathrm{b}}$, Koldo Osoro ${ }^{\mathrm{a}}$ \\ ${ }^{a}$ SERIDA, Área de Sistemas de Producción Animal, 33300 Villaviciosa, Asturias, Spain \\ ${ }^{\mathrm{b}}$ Departamento de Silvopascicultura, Universidad Politécnica de Madrid, 28040 Madrid, Spain \\ Received 17 October 2006; received in revised form 23 May 2007; accepted 25 May 2007
}

\begin{abstract}
Air temperature is one of the most important factors affecting vegetation and controlling key ecological processes. Air temperature models were compared in a mountainous region (Asturias in the North of Spain) derived from five geostatistical and two regression models, using data for January (coolest month) and August (warmest month). The geostatistical models include the ordinary kriging $(\mathrm{OK})$, developed in the $X Y$ plane and in the $X, Y$ and $Z$-axis (OKxyz), with zonal anisotropy in the $Z$-axis (variogram fitting procedure developed in this study), and three techniques that introduce elevation as an explanatory variable: ordinary kriging with external drift (OKED) and universal kriging, using the ordinary least squares (OLS) residuals to estimate the variogram (UK1) or the generalised least squares (GLS) residuals (UK2). The OKED, UK1 and UK2 techniques were more satisfactory than OK in terms of standard prediction error and mean absolute error, which were inferior by $1{ }^{\circ} \mathrm{C}$, but OKxyz improved the results obtained with those techniques. Moreover, OKxyz, OKED, UK1 and UK2 improved slightly the results of a regression model with UTM coordinates and elevation data as independent variables in terms of bias (R1); whereas a complex regression model, which includes altitude, latitude, distance to the sea and solar radiance as independent variables (R2), showed better results in terms of mean absolute error, under $0.16{ }^{\circ} \mathrm{C}$ for both months. A second validation carried out with stations discarded for the interpolation showed a greater similarity between the efficiency of R2 and the geostatistical techniques.
\end{abstract}

(C) 2007 Elsevier B.V. All rights reserved.

Keywords: Climate; Kriging; Mapping; Regression analysis; DEM

\section{Introduction}

Air temperature is one of the input variables for land evaluation and characterisation systems, as well as hydrological and ecological models. These models use air temperature to drive processes such as evapotranspiration, soil decomposition, and plant productivity (Dodson and Marks, 1997). Hence, forest management and research need this climatic variable as a basis for understanding many processes, as it is the main factor

\footnotetext{
* Corresponding author.

E-mail address: rbenavides@serida.org (R. Benavides).
}

affecting vegetation distribution, in the sense that its action is felt over wide areas of the earth's surface (De Phillips, 1951).

Air temperature is an important site characteristic used in determining site suitability for agricultural and forest crops (Hudson and Wackernagel, 1994), and it is used in parameterizing the habitat of plant species (Rubio et al., 2002; Sánchez-Palomares et al., 2003) and in determining the patterns of vegetational zonation (Richardson et al., 2004). Moreover, air temperature is a factor related to plant productivity, as it is connected with the length of the vegetative period and evapotranspiration. Different indexes have been developed for relationships between components of climate and 
quantitative variables of vegetation communities. These indexes are known as potential productivity indexes, and they are reviewed in Serrada (1976), Hägglund (1981) and Del Valle (2004). Finally, temperature can be also considered as a limitation factor, and many studies have been carried out with temperature as a threshold for different processes, e.g. the minimum temperature which may lead to lethal damage of tissue or whole tree seedlings under different situations of stand density, topography or soil preparation (Blennow, 1993, 1998).

Therefore, spatial modelling of climate variables, such as air temperature, is of interest for forestry science. However, these variables are not easy to obtain because they appear as measurements at discrete points. Consequently, many different methods have been developed to generate regional maps from point data, based on the continuity of temperature and its strong dependency on elevation; on a global average, temperature decreases around $0.65{ }^{\circ} \mathrm{C} / 100 \mathrm{~m}$ in altitude (Barry and Chorley, 1987; Gandullo, 1994; Lutgens and Tarbuck, 1995), although this rate may vary with the season and the geographic situation (Goodale et al., 1998), and in relation to diurnal effects (Richardson et al., 2004).

Different interpolation methods have been used to model the spatial distribution of air temperature; the most widely used being the inverse distance interpolation weighting, Voronoi tessellation, regression analysis or, more recently, geostatistical methods. Kurtzman and Kadmon (1999) compared different methods (splines, inverse distance weighting and multiple regression analysis) for daily mean minimum and maximum temperatures in Israel; Sánchez-Palomares et al. (1999) developed maps of climate variables with polynomial regressions based on the $X$ and $Y$ coordinates and elevation in Spain. Relationships have been derived between temperature and other topographic variables, together with elevations, such as exposure, continentality, latitude, and solar radiation. For example, Goodale et al. (1998) and Ninyerola et al. (2000, 2005) used regression analysis and GIS techniques to model different climate components in Ireland and Spain, respectively. Marquínez et al. (2003) related rainfalls in Asturias (Spain) with variables such as distance to the sea and to the West (due to the dominance of fronts from NW). Geostatistical techniques have also been used: Lapen and Hayhoe (2003) compared inverse distance weighting to geostatistical methods (ordinary kriging $(\mathrm{OK})$ and cokriging, and ordinary kriging with external drift (OKED)) to spatially model the seasonal and annual temperature and total precipitation normals in the Great Lakes (Ontario, Canada); Hudson and Wackernagel (1994) mapped air temperature of Scotland using ordinary kriging with external drift; and Ishida and Kawashima (1993) used different kriging estimators, specially cokriging estimators, to evaluate the usefulness of these approaches in temperature modelling in Japan. Approaches that include altitude (or depth) as a spatial dimension (as ordinary kriging with $Z$ anisotropy) have been successfully applied for natural resources estimation (Ayalew et al., 2002; Montes et al., 2005), but these approaches have never been used for predicting climatic variables.

Air temperature modelling in mountainous regions is difficult and challenging ( $\mathrm{Li}$ et al., 2005). Meteorological stations are often spread sparsely, especially at high elevation or in uninhabited areas (Rolland, 2002). Thus, it is difficult to obtain precise climatic maps (Carrega, 1995) because reconstruction of temperature fields involves interpolating sparse data over large distances (Dodson and Marks, 1997). The majority of studies made in places with complex topography have used regression models to obtain the lapse rates, with elevation data as the unique independent variable (Dodson and Marks, 1997; Rolland, 2002) or together with others, such as slope, exposure or distance to the sea (Carrega, 1995).

This study aimed to compare different geostatistical approaches and regression models to spatially predict mean air temperature in January (winter) and August (summer) in a mountainous region of Northern Spain.

\section{Material and methods}

\subsection{Study area}

This comprised the Region of Asturias in Northern Spain, covering an area of $10,604 \mathrm{~km}^{2}$. Its Northern boundary is the Cantabrian Sea (with a coastline of $519 \mathrm{~km}$ ), and the Southern natural border is the Cantabrian Mountains (Fig. 1). This region is characterised by a steep relief, with altitudes ranging from sea level to $2648 \mathrm{~m}$ within only $40 \mathrm{~km}$, and with $80 \%$ of the land exceeding slopes of $20 \%$ and $34.5 \%$ of the territory over $50 \%$ (SADEI, 2005).

\subsection{Data}

Mean air temperature data in January (coolest month) and August (warmest month) were obtained from 96 meteorology stations of the National Meteorology Institute (INM) of the Spanish Government 


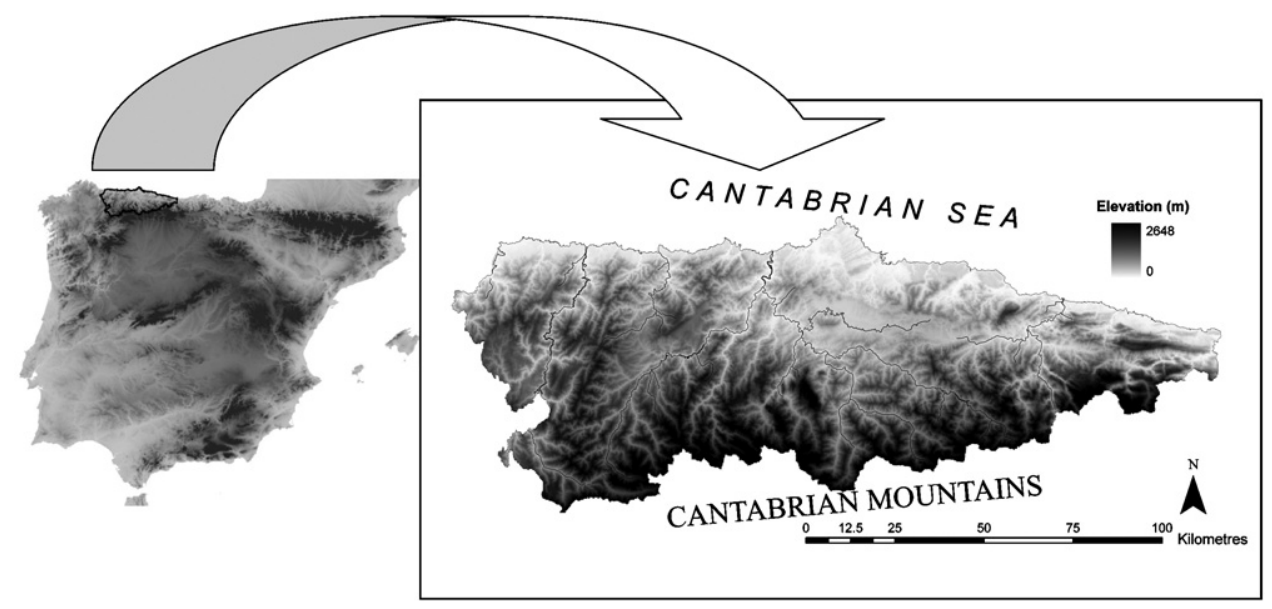

Fig. 1. Location of the study area.

dispersed throughout Asturias. Most of them are located in the central part of the region, which is relatively flat and more populated, while a small number of stations were in areas of complex topography in the South, West and East of the region. Hence, the spatial distribution of the selected stations in the study area was strongly biased towards low elevations: about $85.9 \%$ of them are situated below $600 \mathrm{~m}$, around $9.4 \%$ between 600 and $1000 \mathrm{~m}$, and only $4.7 \%$ over $1000 \mathrm{~m}$. The biased location of stations poses a problem in modelling temperature because almost $20 \%$ of the territory is located over $1000 \mathrm{~m}$. For this reason, another 60 stations in surrounding regions, belonging to the INM, were also considered to make up for the scarcity of data in some areas. Counting these stations of nearby provinces, the number of stations over $1000 \mathrm{~m}$ reached $24.7 \%$ of the total 156 stations (96 in Asturias and 60 in nearby provinces).

A Digital Elevation Model (DEM) of Asturias was used as ancillary data, with an accuracy of $90 \mathrm{~m}$, and it was obtained from the Department of Topography of the Forest Engineering College (Polytechnic University of Madrid). Prediction points have been obtained from this DEM, and belong to a grid of $500 \mathrm{~m} \times 500 \mathrm{~m}$, totalling 42,438 prediction points with its respective UTM coordinates and elevations. Thus, the accuracy of the resulting models was a pixel size of $0.25 \mathrm{~km}^{2}$. Most air temperature models use a pixel size of at least $1 \mathrm{~km} \times 1 \mathrm{~km}$ (Hudson and Wackernagel, 1994; Dodson and Marks, 1997; Goodale et al., 1998; Hayhoe and Lapen, 2001). However, elevation and temperature can vary dramatically within $1 \mathrm{~km}^{2}$, particularly in mountainous regions, e.g. with a slope of $50 \%, 1 \mathrm{~km}$ means an altitude difference of $500 \mathrm{~m}$, which results in a temperature difference of $3.25{ }^{\circ} \mathrm{C}\left(0.65{ }^{\circ} \mathrm{C} / 100 \mathrm{~m} \times 5\right)$.
Hence, in this study a smaller grid is chosen because of the steep slopes found in Asturias. Furthermore, this precision $(500 \mathrm{~m} \times 500 \mathrm{~m})$ still brings an acceptable volume of data in terms of computing-time and capacity.

\subsection{Filtering data}

According to the definition of the World Meteorological Organisation (WMO), data for a 30-year period are recommended because they provide stable and reproducible monthly means (Fliri, 1975; Gafta and Pedrotti, 1996). Therefore, the mean temperatures used in this study were assessed from 1970 to 2000 data sets. Only 23 stations in August and 19 in January of the 156 stations had complete data series during that period of time. In order to select more appropriate stations for this study, two criteria were established for selection: (1) those stations with recorded data in at least 15 years of the series; and (2) those with data which had a Pearson correlation coefficient with the stations with complete data, of higher than 0.7 . Only 77 stations in each month fulfilled these requirements, including the complete ones, so the air temperature models were built from the August and January monthly means of these 77 stations (Fig. 2).

A Homogeneity or Runs Test (Thom, 1966) was used to determine whether the order of occurrence of two values of the variable was random, and the results showed that no temporal trends within the mean temperature series existed.

Once the suitability of the sample length and homogeneity had been checked, missing data during the study period were estimated. This was achieved by linear regression between stations with incomplete and 


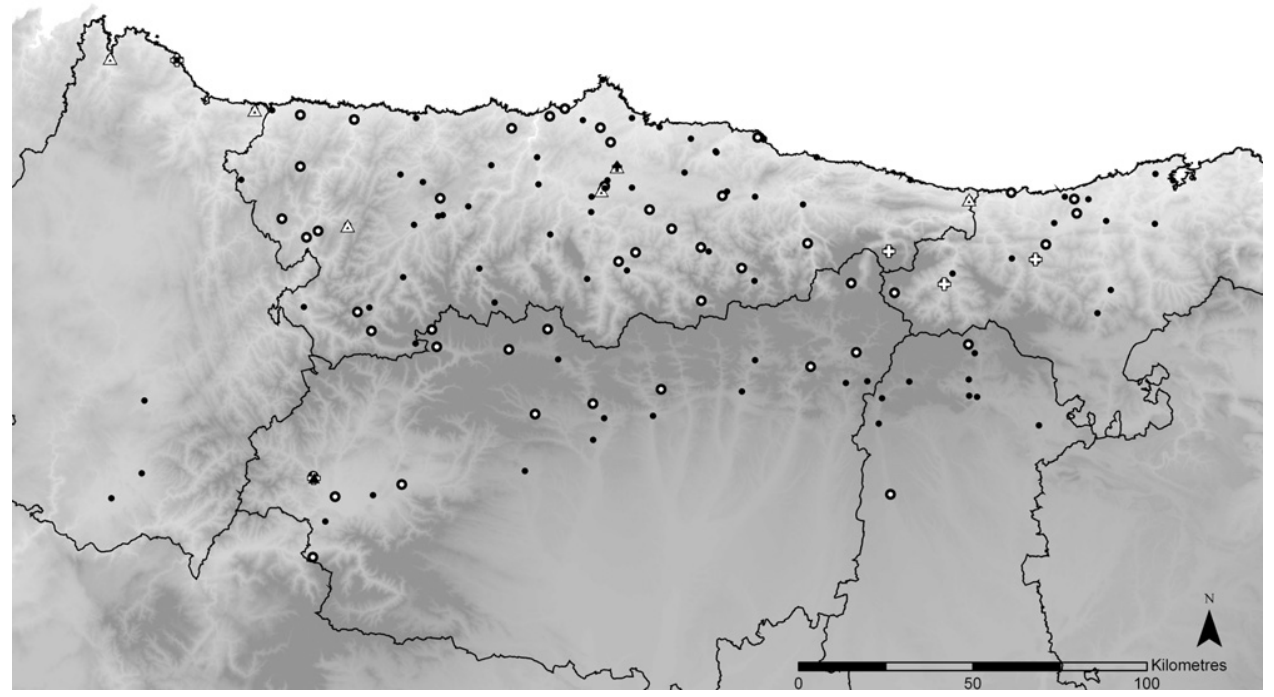

Fig. 2. Location of the selected stations for mean temperature prediction (white) and stations used for data validation (black). Circles represent stations with data for January and August; triangles represent stations only with January data; crosses represent stations only with August data.

complete data using the stepwise approach. This method has the advantage that one variable selected in one step can be eliminated in another step. The estimated data comprised $19.61 \%$ of the total data used in the interpolation methods.

\subsection{Geostatistical methods}

Geostatistics comprise a set of techniques and estimators which use the spatial variability and correlation of a continuous spaced-distributed phenomenon to predict at unsampled locations. They consist generally of two steps: a preliminary data exploratory and structural analysis of the information in order to describe the spatial variability of the variable, and the spatial prediction at unsampled points.

\subsubsection{Spatial variance model: the variogram}

The spatial autocorrelation was characterised through the experimental semivariogram. The semivariogram (usually abbreviated to variogram) measures the average dissimilarity between data separated by a lag $h$. It is calculated as half the average squared difference between the components of data pairs (semivariance):

$\hat{\gamma}(h)=\frac{1}{2 N(h)} \sum_{a=1}^{N(h)}\left[z\left(u_{a}\right)-z\left(u_{a}+h\right)\right]^{2}$

where $N(h)$ is the number of pairs of data locations a vector $h$ apart, $z\left(u_{a}\right)$ and $z\left(u_{a}+h\right)$ are measurements at locations $u_{a}$ and $u_{a}+h$, respectively, which are con- sidered as single realisations of the random function $Z(u)$ defined over the domain $D$ of $R^{2}$.

Then, the experimental variograms were modelled using the spherical model (Goovaerts, 1999), to which a nugget effect was added, and the Gaussian model (Cressie, 1993).

The theoretical variogram model was fitted from the experimental variogram using the minimum weighted squares method (Cressie, 1993). The performance of the fitted variogram at small scales, which are the most important in the spatial prediction (Hudson and Wackernagel, 1994), was checked by comparing the plots of the theoretical model fitted and the experimental variogram.

\subsubsection{Spatial prediction}

2.4.2.1. Ordinary kriging in the $X Y$ plane $(O K)$. The ordinary kriging prediction of $Z(u)$ at location $u_{a}$ is given by the following equation:

$z^{*}\left(u_{a}\right)=\sum_{i=1}^{n} \lambda_{i}\left(u_{a}\right) z\left(u_{i}\right)$

where $\lambda_{a}(u)$ is the assigned weight for data $z\left(u_{i}\right)$ from the $n$ sampled locations, so that the estimation of error variance (Eq. (3)) was minimised, under the constraint of unbiasedness of the estimator (Eq. (4)).

$\sigma_{E}^{2}=\operatorname{Var}\left\{Z^{*}\left(u_{a}\right)-Z\left(u_{a}\right)\right\}$

$\sum_{i=1}^{n} \lambda_{i}=1$ 
2.4.2.2. Ordinary kriging in the $X, Y$ and $Z$-axis with zonal anisotropy on the Z-axis (OKxyz). As occurs with depth in geosciences, when elevation is included in the kriging system the directional variograms show zonal anisotropy, i.e. the variogram for stations aligned through the $X Y$ plane show different sill (the semivariance value where the variogram gets stable) than for stations located at different elevation ( $Z$-axis).

When observations are available in all directions, as usually occurs with geological surveys, the anisotropy may be modelled directly from the directional experimental variograms (Gringarten and Deutsch, 2001). However, the terrain configuration impedes air temperature observations aligned through the vertical direction. Those pairs of stations forming an angle with the horizontal greater than $1.75^{\circ}$ were selected to calculate the directional variogram for the $Z$-axis, whereas those pairs of stations forming an angle with the horizontal smaller than $0.75^{\circ}$, and with elevation difference no greater than $300 \mathrm{~m}$, were selected to calculate the $X Y$ variogram. For each lag, the vertical component of the distance was averaged across all pairs of observations, both in the $X Y$ plane and in the $Z$ direction variograms. The key step when dealing with zonal anisotropy is to build a strictly negative definite model (Rouhani and Myers, 1990; Myers and Journel, 1990). Both directional variograms were modelled as the sum of an isotropic spherical variogram and a Gaussian variogram for the $Z$-axis, which constitutes a valid model (De Iaco et al., 2002):

$\gamma(d)=\gamma_{\text {spherical }}(x, y, z)+\gamma_{\text {Gaussian }}(z)$

Ordinary kriging was carried out calculating the sum variogram for each pair of observations for each observation-prediction point.

\subsubsection{Ordinary kriging with external drift (OKED).} The spatial prediction was carried out over the residuals $(\delta(u))$ of a regression model of $Z(u)$ as a function of the explanatory variable $Y(u)$ :

$z\left(u_{a}\right)=a_{0}+a_{1} y\left(u_{a}\right)+\delta\left(u_{a}\right)$

The predicted values are the addition of the regression estimates of $Z(u)$ at each location and the residuals estimated through ordinary kriging at each location.

2.4.2.4. Universal kriging $(U K) . Z(u)$ is given by the following linear model of $p$ known functions $f_{k}(u)$ :

$z\left(u_{a}\right)=\sum_{k=0}^{p} \beta_{k} f_{k}\left(u_{a}\right)+\delta\left(u_{a}\right)$
Eq. (2) holds, and the unbiasedness condition becomes:

$\sum_{i=1}^{n} \lambda_{i} f_{j-1}\left(u_{i}\right)=f_{j-1}\left(u_{a}\right)$

To obtain the $\lambda_{i}$ coefficients in Eq. (2) the error variance given by Eq. (9) is minimised:

$$
\begin{aligned}
\sigma_{E}^{2}= & \left(\sum_{k=0}^{p} \beta_{k} f_{k}\left(u_{a}\right)+\delta\left(u_{a}\right)\right. \\
& \left.-\sum_{i=1}^{n}\left(\lambda_{i} \sum_{k=0}^{p} \beta_{k} f_{k}\left(u_{i}\right)\right)-\sum_{i=1}^{n} \lambda_{i} \delta\left(u_{i}\right)\right)^{2}
\end{aligned}
$$

Two different procedures have been carried out to estimate the variogram for UK. The first variogram estimation (UK1) was based on the residuals of ordinary least squares (OLS) $\beta_{k}$ estimates of Eq. (7) (which in turn coincides with the variogram used in the OKED method). Thereafter, the universal kriging estimator will be carried out with these variogram's parameters to krige the values of the variable. Unfortunately, the variogram computed with the OLS residuals yields a biased estimator of the true variogram (Cressie, 1993). The second procedure, referred to as UK2 and developed by Neuman and Jacobson (1984), consists of iteratively fitting the variogram (starting with the variogram based on the OLS residuals) and obtaining the generalised least squares (GLS) estimates of the $\beta_{k}$ coefficients through Eq. (10):

$\hat{\boldsymbol{\beta}}_{\mathrm{GLS}}=\left(\boldsymbol{X}^{\prime} \boldsymbol{\Sigma}(\hat{\boldsymbol{\theta}})^{-1} \boldsymbol{X}\right)^{-1} \boldsymbol{X}^{\prime} \boldsymbol{\Sigma}(\hat{\boldsymbol{\theta}})^{-1} \boldsymbol{Z}$

where $\hat{\boldsymbol{\beta}}_{\mathrm{GLS}}$ is the vector of the coefficients, $\boldsymbol{X}$ an $n \times(p+1)$ matrix whose $(a, j)$ element is $f_{j-1}\left(u_{a}\right), \boldsymbol{Z}$ the column vector of the $z\left(u_{a}\right)$ values in the $n$ sampled locations and $\boldsymbol{\Sigma}(\hat{\boldsymbol{\theta}})$ is the $\operatorname{Var}(\boldsymbol{Z})$ matrix based on the parameters $(\hat{\boldsymbol{\theta}})$ of the fitted variogram. The variogram based on the GLS residuals does not solve the bias problem, although this bias usually has little effect on the spatial prediction (Cressie, 1993).

\subsection{Regression models}

The first regression model for the Iberian Peninsula (R1) was developed by Sánchez-Palomares et al. (1999) and it was based on stepwise multiple regression analysis, which was carried out for each month and for each of the 10 main basins previously described in the Iberian Peninsula. The models of the mean temperature for January $\left(T_{\mathrm{J}}\right)$ and for August $\left(T_{\mathrm{A}}\right)$ presented these forms for Asturias: 


$$
\begin{aligned}
& T_{\mathrm{J}}=2490.96-5.66\left(\frac{e}{10^{3}}\right)-104.46\left(\frac{Y}{10^{5}}\right)+1.10\left(\frac{Y}{10^{5}}\right)^{2} \\
& T_{\mathrm{A}}=-2157.01-4.05\left(\frac{e}{10^{3}}\right)+0.89\left(\frac{X}{10^{5}}\right)+93.57\left(\frac{Y}{10^{5}}\right)-0.11\left(\frac{X}{10^{5}}\right)^{2}-1.01\left(\frac{Y}{10^{5}}\right)^{2}
\end{aligned}
$$

Elevation $(e)$ and UTM coordinates in metres ( $X$ is the UTM coordinate in the $x$-axis, and $Y$ in the $y$-axis).

The other used model (R2) was developed by Ninyerola et al. (2005). In this model, together with elevation $(e)$ and UTM coordinates, in this case latitude $(L)$, they introduced new independent variables, thanks to the Geographical Information Systems (GIS) techniques. These were the continentality $(C)$ measured as the linear distance to the sea, the solar radiance (obtained from a DEM and astronomical equations) $(R)$, and the geomorphology or curvature radius of the terrain also derived from the Digital Elevation Model and which was used to develop the continentality variable. It presented the following expression:

$T=b_{0}+b_{1} e+b_{2} L+b_{3} C+b_{4} R$

Then, a correction of the estimated residuals was accomplished. Temperature values at the sampled points are obtained directly from the Digital Climatic Atlas of the Iberian Peninsula, available free on-line (http://opengis.uab.es/wms/iberia/mms/index.htm).

\subsection{Validation and techniques comparison}

To compare the performance of the five geostatistical methods, the results of the leave-one-out crossvalidation were analysed (Stone, 1974; Geisser, 1975), as well as the distribution of the prediction errors in the estimation points. Besides, data from the stations, which were rejected for the interpolation, were also used to verify the goodness of our models, above all in faraway locations.

The leave-one-out cross-validation or jackknifing is a commonly applied method in geostatistics (Isaaks and Srivastava, 1989; Cressie, 1993; Nalder and Ross, 1998) because no reserved data are required for the data validation. The number of sampled sites with climatic data is usually not very large and they are sparse throughout the study area, so all the sampled data are used for the spatial prediction in order to improve the precision of the predictions. The cross-validation procedure was carried out as follows: each datum was removed and predicted from its neighbours $\left(\hat{Z}_{-a}\left(u_{a}\right)\right)$. Then, estimated and observed values were compared. The normalised mean error or $\operatorname{NME}\left(E_{1}\right)$ was used to check whether the kriging prediction was approximately unbiased (the NME should be approximately 0):

$E_{1}=\frac{1}{n} \sum_{a=1}^{n}\left\{\frac{\left(Z\left(u_{a}\right)-\hat{Z}_{-a}\left(u_{a}\right)\right)}{\sigma_{-a}\left(u_{a}\right)}\right\}$

The normalised root mean squared error or NRMSE $\left(E_{2}\right)$ was used to check whether the kriging prediction error based on the fitted variogram was satisfactory, in which case the NRMSE should be approximately 1:

$E_{2}=\left[\frac{1}{n} \sum_{a=1}^{n}\left\{\frac{\left(Z\left(u_{a}\right)-\hat{Z}_{-a}\left(u_{a}\right)\right)}{\sigma_{-a}\left(u_{a}\right)}\right\}^{2}\right]^{1 / 2}$

Cross-validation only provides information on areas associated with observed data (Robeson, 1994), so it should not be used for confirmatory data analysis, such as standard error estimation. Thus, the kriging standard error $\left(\sigma_{\mathrm{OK}}\left(u_{a}\right)\right.$ and $\sigma_{\mathrm{UK}}\left(u_{a}\right)$, given by Eqs. $(15)$ and (16), respectively) was assessed at the prediction points, which quantifies the uncertainty in the predicted surface.

$$
\begin{aligned}
\sigma_{\mathrm{OK}}^{2}\left(u_{a}\right)= & \sum_{i=1}^{n} \lambda_{i} \gamma\left(u_{a}-u_{i}\right)-\frac{1-\mathbf{1}^{\prime} \boldsymbol{\Gamma}^{-1} \boldsymbol{\gamma}}{\mathbf{1}^{\prime} \boldsymbol{\Gamma}^{-1} \mathbf{1}} \\
\sigma_{\mathrm{UK}}^{2}\left(u_{a}\right)= & \boldsymbol{\gamma}^{\prime} \boldsymbol{\Gamma}^{-1} \boldsymbol{\gamma}-\left(\boldsymbol{x}-\boldsymbol{X}^{\prime} \boldsymbol{\Gamma}^{-1} \boldsymbol{\gamma}\right)\left(\boldsymbol{X}^{\prime} \boldsymbol{\Gamma}^{-1} \boldsymbol{X}\right) \\
& \times\left(\boldsymbol{x}-\boldsymbol{X}^{\prime} \boldsymbol{\Gamma}^{-1} \boldsymbol{\gamma}\right)
\end{aligned}
$$

where $\mathbf{1}$ is the column matrix of ones, $\mathbf{1}^{\prime}$ the row matrix of ones, $\gamma$ the column vector of the semivariogram values between $u_{a}$ and $u_{i}\left(\gamma\left(u_{a}-u_{i}\right)\right), \Gamma$ the matrix with the $(i, j)$ th $\left(\gamma\left(u_{i}-u_{j}\right)\right), \boldsymbol{x}$ the vector of the $p f_{k}\left(u_{a}\right)$ values and $\boldsymbol{X}$ is the $n \times(p+1)$ matrix whose $(a, j)$ element is $f_{j-1}\left(u_{a}\right)$.

For the geostatistical and the regression models the mean error (ME) $-M_{1}$ - and the mean absolute error (MAE) $-M_{2}$ - at the observed points were computed to determine the accuracy of the different estimation approaches:

$$
\begin{aligned}
& M_{1}=\frac{1}{n} \sum_{a=1}^{n}\left(Z\left(u_{a}\right)-\hat{Z}_{-a}\left(u_{a}\right)\right) \\
& M_{2}=\frac{1}{n} \sum_{a=1}^{n}\left|Z\left(u_{a}\right)-\hat{Z}_{-a}\left(u_{a}\right)\right|
\end{aligned}
$$


Stations not used for the spatial model, with at least 5 years data, were selected to carry out a validation over an independent data set (52 stations in January and 51 in August). The prediction error, ME and MAE were calculated for the different techniques. Many of these stations were located in areas with sparse data (Fig. 2), and the proportion of these stations over $600 \mathrm{~m}$ exceeded the proportion of those used in the interpolation $(42.3 \%$ for January and $43.1 \%$ for August). Accordingly, the independent data set was used to check the performance of the different prediction techniques in areas with few observations or at high altitudes.

\section{Results}

\subsection{Geostatistical models}

The correlation between temperature $(T)$ and elevation $(e)$ in the OLS regression model was negative and significant at 0.01 level, two-tailed ( $\rho=-0.75$ for August temperatures and $\rho=-0.93$ for the mean temperature of January). The OLS regression was the following:

$T_{\mathrm{J}}=90.85-0.065 e$

$T_{\mathrm{A}}=196.99-0.026 e$

The iterative approach used to fit the variogram and the GLS estimates of the $\beta_{k}$ coefficients, Eq. (10), resulted in $\beta_{0}=99.051$ and $\beta_{0}=164.161$ (the intercept) and $\beta_{1}=-0.077$ and $\beta_{1}=-0.009$ (coefficient of the elevation variable) for January and August, respectively.

Fig. 3 shows the experimental variogram for the air temperature and the spherical model fitted for OK, and the directional variograms in the $X Y$ plane and $Z$-axis, as well as the fitted spherical plus Gaussian model for the OKxyz. The variogram for the OLS and the GLS residuals and the fitted spherical models (for OKED and UK1, and for UK2, respectively) can also be seen. The parameters for the fitted theoretical variogram models are shown in Table 1. It can be observed that there was negligible nugget effect, i.e. distance near nought means variogram - variance - close to nought, which agreed with the continuous nature of this variable; and the sill or variance value in January was higher than in August, according to a higher variability of the data in winter.

\subsection{Prediction and modelling of mean temperature}

The maps of January and August mean temperature derived from the five geostatistical and the two regression methods are shown in Figs. 4 and 5, respectively. A progressive cooler gradient can be observed when moving from the coastline to the South (to the mountains), and some exceptional cooler areas can be found near the coast due to the high altitudes of some sierras which are very close to the coast. Warm areas occurred in middle-high parts of the main basins.

In winter, the Western coast was warmer than the Eastern coast. This is probably due to the Eastern part of Asturias is more affected by the European Anticyclone in winter, which brings cold, dry air. In the Western part of Asturias, the climate is often influenced by subtropical winds from the SW, which bring clouds and rain (García and Reija, 1994). In summer, the warm interior regions coincided with the warmest areas. This phenomenon points the "muffle effect" of the sea.

Comparing the techniques, there were great differences between ordinary kriging and the other techniques, which accommodate elevation data, as shown in Figs. 4 and 5 and Table 2. These differences were higher in winter, when the correlation between mean temperature and altitude was higher.

Table 1

Parameters of the fitted variograms for January and August data with the different methods

\begin{tabular}{|c|c|c|c|c|c|}
\hline & Type of adjustment & Month & Nugget $\left({ }^{\circ} \mathrm{C}^{2}\right)$ & Sill $\left({ }^{\circ} \mathrm{C}^{2}\right)$ & Range (km) \\
\hline \multirow[t]{2}{*}{ Ordinary kriging } & \multirow[t]{2}{*}{ Spherical } & January & 0.000 & 9.855 & 104.7 \\
\hline & & August & 0.021 & 2.146 & 59.3 \\
\hline \multirow{4}{*}{$\begin{array}{l}\text { Ordinary kriging } X Y Z \text { with zonal } \\
\text { anisotropy in the } Z \text {-axis }\end{array}$} & \multirow[t]{2}{*}{ Spherical (xyz) } & January & 0.489 & 1.205 & 144.3 \\
\hline & & August & 0.243 & 0.644 & 136.9 \\
\hline & \multirow[t]{2}{*}{ Gaussian (z) } & January & 0.000 & 21.764 & 0.9 \\
\hline & & August & 0.000 & 6.039 & 0.6 \\
\hline \multirow{2}{*}{$\begin{array}{l}\text { Ordinary kriging with external drift } \\
\text { and universal kriging } 1\end{array}$} & \multirow[t]{2}{*}{ Spherical } & January & 0.370 & 1.050 & 22.4 \\
\hline & & August & 0.000 & 0.732 & 31.4 \\
\hline \multirow[t]{2}{*}{ Universal kriging 2} & \multirow[t]{2}{*}{ Spherical } & January & 0.493 & 1.403 & 28.6 \\
\hline & & August & 0.000 & 1.337 & 43.1 \\
\hline
\end{tabular}



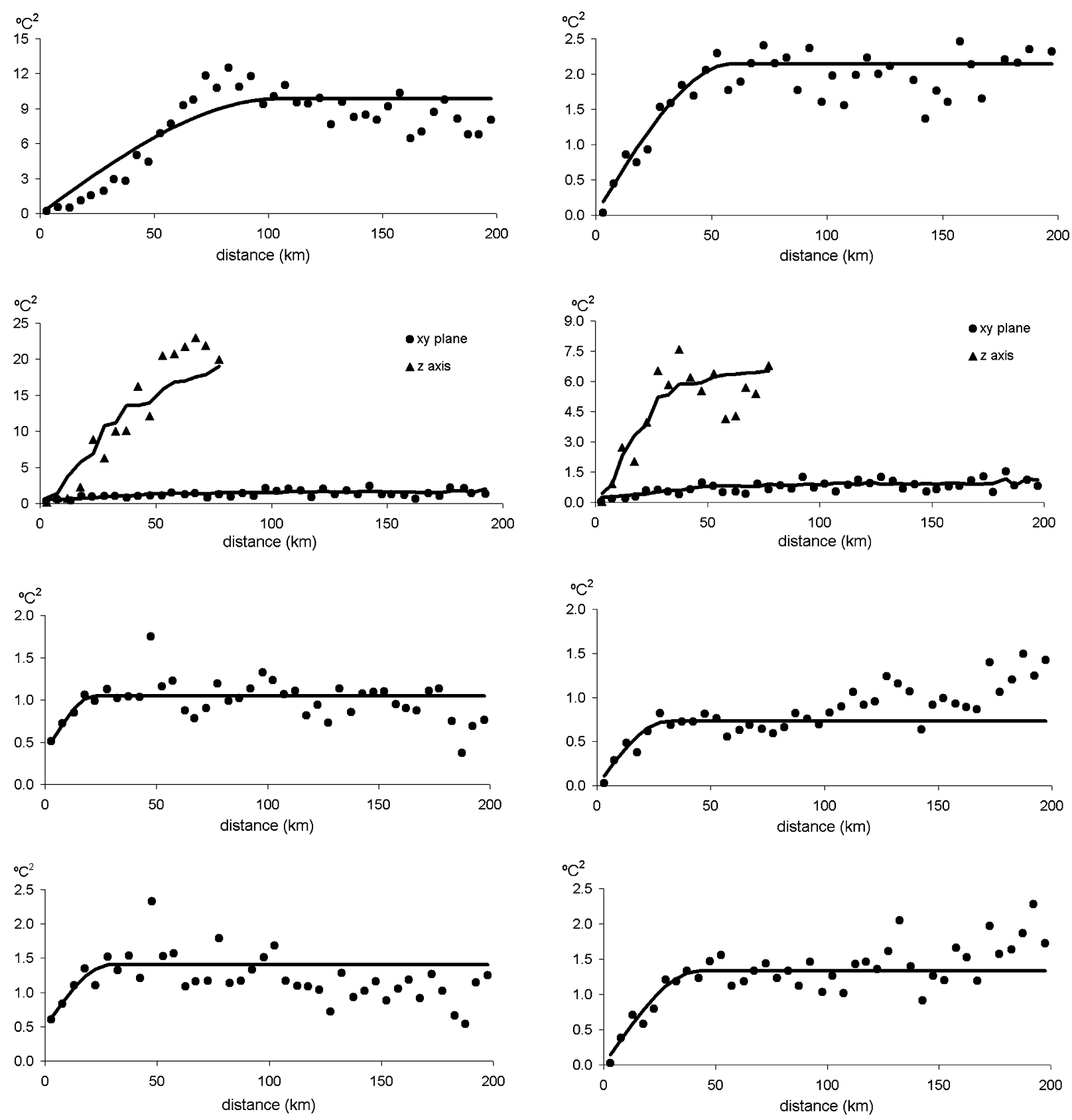

Fig. 3. Variograms of (a) January and (b) August: (1) for mean temperatures with ordinary kriging, (2) for mean temperatures with ordinary kriging in 3D, (3) for ordinary least squares residuals (ordinary kriging with external drift and universal kriging (1), (4) for generalised least squares residuals obtained for universal kriging 2.

The January mean temperature with OK was around $2{ }^{\circ} \mathrm{C}$ higher than the rest. This differential increased, reaching nearly $4{ }^{\circ} \mathrm{C}$, when only stations over $600 \mathrm{~m}$ were considered, and exceeding $8{ }^{\circ} \mathrm{C}$ for the minima. The three-dimensional OK (OKxyz) presented seemingly similar results to the multivariate ones on average terms. However, the minimum temperatures of
OKxyz at high altitudes, and similarly to OK, showed noticeable differences with the multivariate techniques.

In August, differences were less, although OK continued estimating higher mean temperatures (around $1{ }^{\circ} \mathrm{C}$ ), and both $\mathrm{OK}$ and OKxyz predicted higher minima at high altitudes (around $2{ }^{\circ} \mathrm{C}$ ) than OKED, UK1 and UK2. 
Table 2

Descriptive statistics of the predicted temperatures

\begin{tabular}{|c|c|c|c|c|c|c|}
\hline & \multicolumn{3}{|l|}{ January } & \multicolumn{3}{|l|}{ August } \\
\hline & $\begin{array}{l}\text { Stations } \\
\text { below } 600 \mathrm{~m}\end{array}$ & $\begin{array}{l}\text { Stations equal } \\
\text { and over } 600 \mathrm{~m}\end{array}$ & $\begin{array}{l}\text { All } \\
\text { stations }\end{array}$ & $\begin{array}{l}\text { Stations } \\
\text { below } 600 \mathrm{~m}\end{array}$ & $\begin{array}{l}\text { Stations equal } \\
\text { and over } 600 \mathrm{~m}\end{array}$ & $\begin{array}{l}\text { All } \\
\text { stations }\end{array}$ \\
\hline \multicolumn{7}{|c|}{ Ordinary kriging } \\
\hline $\operatorname{Min}\left({ }^{\circ} \mathrm{C}\right)$ & 4.5 & 2.8 & 2.8 & 16.6 & 14.7 & 14.7 \\
\hline $\operatorname{Max}\left({ }^{\circ} \mathrm{C}\right)$ & 10.0 & 9.3 & 10.0 & 20.6 & 20.5 & 20.6 \\
\hline Mean $\left({ }^{\circ} \mathrm{C}\right)$ & 8.1 & 6.1 & 7.1 & 19.0 & 18.6 & 18.8 \\
\hline S.D. $\left({ }^{\circ} \mathrm{C}\right)$ & 1.0 & 1.4 & 1.5 & 0.5 & 1.1 & 0.9 \\
\hline \multicolumn{7}{|c|}{ Ordinary kriging in $3 \mathrm{D}$} \\
\hline $\operatorname{Min}\left({ }^{\circ} \mathrm{C}\right)$ & 4.7 & 1.7 & 1.7 & 17.1 & 14.2 & 14.2 \\
\hline $\operatorname{Max}\left({ }^{\circ} \mathrm{C}\right)$ & 9.4 & 7.5 & 9.4 & 20.2 & 18.7 & 20.2 \\
\hline Mean $\left({ }^{\circ} \mathrm{C}\right)$ & 7.5 & 3.6 & 5.7 & 18.8 & 16.4 & 17.7 \\
\hline S.D. $\left({ }^{\circ} \mathrm{C}\right)$ & 1.0 & 1.1 & 2.2 & 0.5 & 0.9 & 1.4 \\
\hline \multicolumn{7}{|c|}{ Ordinary kriging with external drift } \\
\hline $\operatorname{Min}\left({ }^{\circ} \mathrm{C}\right)$ & 4.5 & -6.7 & -6.7 & 16.6 & 12.8 & 12.8 \\
\hline $\operatorname{Max}\left({ }^{\circ} \mathrm{C}\right)$ & 9.9 & 6.5 & 9.9 & 20.6 & 19.8 & 20.6 \\
\hline Mean $\left({ }^{\circ} \mathrm{C}\right)$ & 7.3 & 2.7 & 5.1 & 18.9 & 17.2 & 18.1 \\
\hline S.D. $\left({ }^{\circ} \mathrm{C}\right)$ & 1.2 & 2.1 & 2.8 & 0.6 & 1.2 & 1.2 \\
\hline \multicolumn{7}{|c|}{ Universal kriging 1} \\
\hline $\operatorname{Min}\left({ }^{\circ} \mathrm{C}\right)$ & 4.5 & -6.3 & -6.3 & 16.6 & 12.2 & 12.2 \\
\hline $\operatorname{Max}\left({ }^{\circ} \mathrm{C}\right)$ & 9.9 & 6.7 & 9.9 & 20.6 & 19.7 & 20.6 \\
\hline Mean $\left({ }^{\circ} \mathrm{C}\right)$ & 7.3 & 2.8 & 5.2 & 18.9 & 17.0 & 18.0 \\
\hline S.D. $\left({ }^{\circ} \mathrm{C}\right)$ & 1.1 & 2.0 & 2.8 & 0.6 & 1.3 & 1.3 \\
\hline \multicolumn{7}{|c|}{ Universal kriging 2} \\
\hline $\operatorname{Min}\left({ }^{\circ} \mathrm{C}\right)$ & 4.5 & -6.1 & -6.1 & 16.6 & 11.8 & 11.8 \\
\hline $\operatorname{Max}\left({ }^{\circ} \mathrm{C}\right)$ & 9.9 & 6.7 & 9.9 & 20.6 & 19.6 & 20.6 \\
\hline Mean $\left({ }^{\circ} \mathrm{C}\right)$ & 7.3 & 2.9 & 5.2 & 18.8 & 16.9 & 17.9 \\
\hline S.D. $\left({ }^{\circ} \mathrm{C}\right)$ & 1.1 & 2.0 & 2.7 & 0.6 & 1.3 & 1.4 \\
\hline \multicolumn{7}{|c|}{ Regression model 1} \\
\hline $\operatorname{Min}\left({ }^{\circ} \mathrm{C}\right)$ & 5.2 & -5.1 & -5.1 & 16.5 & 10.6 & 10.6 \\
\hline $\operatorname{Max}\left({ }^{\circ} \mathrm{C}\right)$ & 9.4 & 5.7 & 9.4 & 20.0 & 18.1 & 20.0 \\
\hline Mean $\left({ }^{\circ} \mathrm{C}\right)$ & 7.3 & 3.0 & 5.3 & 18.3 & 16.0 & 17.3 \\
\hline S.D. $\left({ }^{\circ} \mathrm{C}\right)$ & 1.1 & 1.9 & 2.6 & 0.6 & 1.2 & 1.5 \\
\hline \multicolumn{7}{|c|}{ Regression model 2} \\
\hline $\operatorname{Min}\left({ }^{\circ} \mathrm{C}\right)$ & 3.4 & -5.0 & -5.0 & 16.3 & 10.6 & 10.6 \\
\hline $\operatorname{Max}\left({ }^{\circ} \mathrm{C}\right)$ & 10.3 & 8.0 & 10.3 & 21.0 & 19.9 & 21.0 \\
\hline Mean $\left({ }^{\circ} \mathrm{C}\right)$ & 7.3 & 3.3 & 5.4 & 18.6 & 16.4 & 17.6 \\
\hline S.D. $\left({ }^{\circ} \mathrm{C}\right)$ & 1.1 & 1.9 & 2.5 & 0.6 & 1.2 & 1.5 \\
\hline
\end{tabular}

The first regression model is the one developed by Sánchez-Palomares et al. (1999) and the second one is the model developed by Ninyerola et al. (2005).

The regression models estimated mean temperatures similar to those of the multivariate spatial models in January, although the minimum temperatures were smoothed. In August, the regression models gave slightly lower mean and minimum temperatures than the multivariate spatial models.

\subsection{Validation and kriging error distribution}

Table 3 shows the NME and NRMSE resulting from the cross-validation for the OK, OKxyz, OKED, UK1 and UK2 methods. The NME was approximately 0 for every kriging technique, which indicated that air 

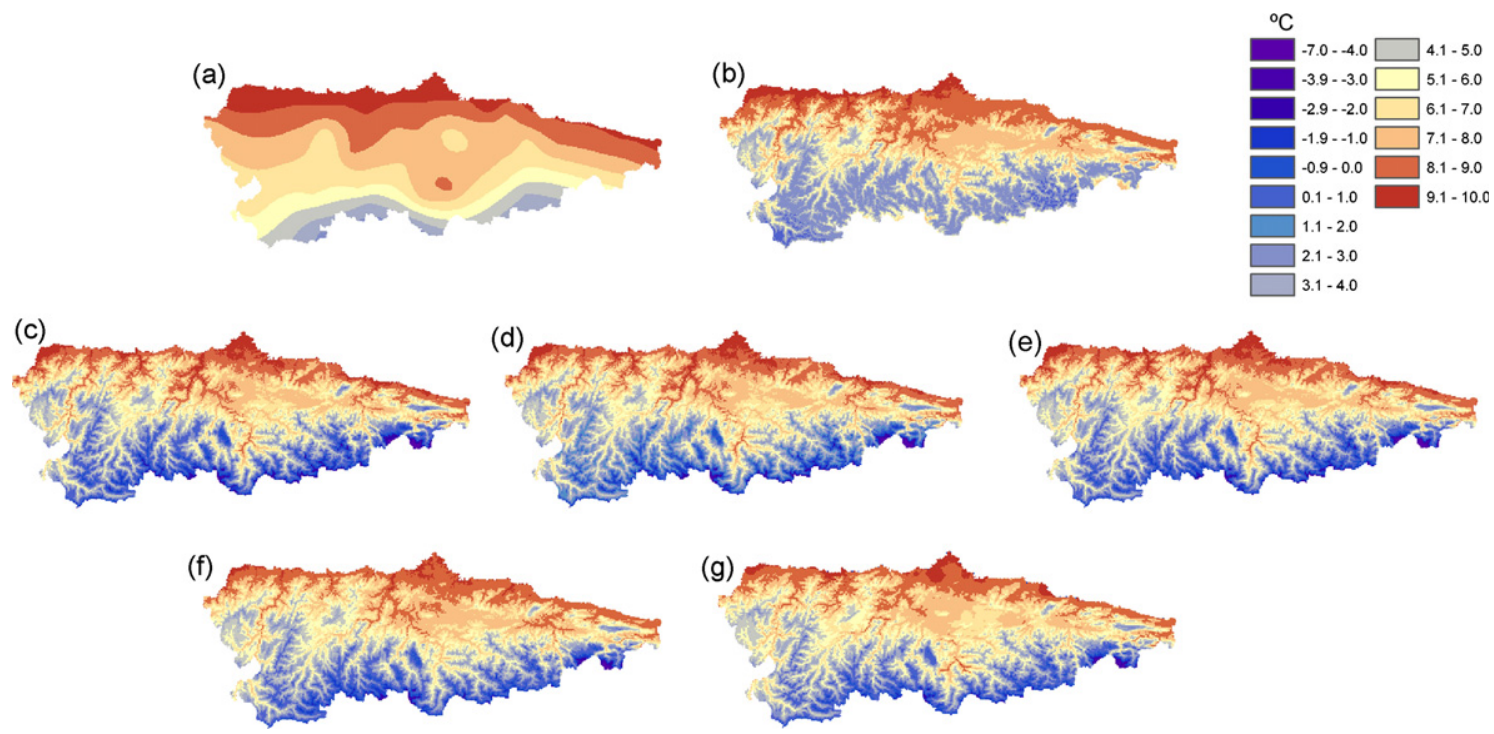

Fig. 4. Models of predicted mean air temperature in January: (a) ordinary kriging, (b) ordinary kriging in 3D, (c) ordinary kriging with external drift (d) universal kriging 1, (e) universal kriging 2, (f) Sánchez-Palomares' regression model, (g) Ninyerola's regression model.

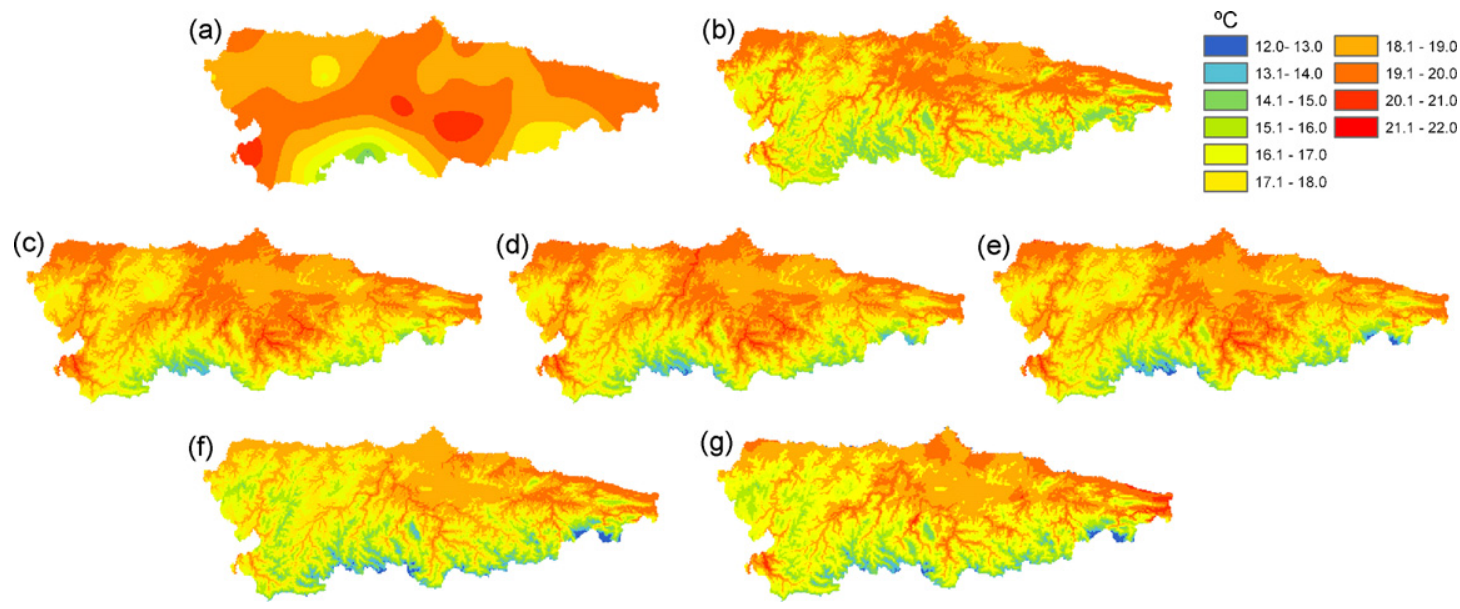

Fig. 5. Models of predicted mean air temperature in August: (a) ordinary kriging, (b) ordinary kriging in 3D, (c) Ordinary kriging with external drift, (d) universal kriging 1, (e) universal kriging 2, (f) Sánchez-Palomares' regression model, (g) Ninyerola's regression model.

Table 3

Normalised mean error (NME) and normalised root mean squared error (NRMSE) of the values inferred by cross-validation, for each technique (OK: ordinary kriging; OKxyz: ordinary kriging in 3D; OKED: ordinary kriging with external drift, UK: universal kriging), and during January and August

\begin{tabular}{|c|c|c|c|c|c|c|c|c|c|c|}
\hline & \multicolumn{5}{|c|}{ January } & \multicolumn{5}{|c|}{ August } \\
\hline & OK & OKxyz & OKED & UK1 & UK2 & $\mathrm{OK}$ & OKxyz & OKED & UK1 & UK2 \\
\hline NME & 0.025 & 0.003 & 0.017 & 0.011 & 0.009 & 0.016 & 0.008 & 0.028 & 0.030 & 0.026 \\
\hline NRMSE & 0.737 & 0.320 & 0.994 & 0.996 & 0.875 & 1.190 & 1.136 & 1.181 & 1.156 & 0.955 \\
\hline
\end{tabular}


temperature estimations were approximately unbiased. The NRMSE of every procedure was approximately 1 , which indicated that the fitted variogram and the consequent kriging standard error were satisfactory. An exception appeared in January with OKxyz, with a low NRMSE, which indicated that the kriging variance tends to overestimate the true error.

The OKED, UK1 and UK2 showed prediction models with similar ranges in the kriging standard error maps (Fig. 5). Nonetheless, the OKxyz, which takes into account the spatial variability in three dimensions, compiled better results than the other models, especially in January and for low altitudes.

In general, August predictions showed smaller errors than January ones, according to a smaller variability of the summer's data. The highest residuals were found in those areas with no or sparsely distributed stations, such as in Navia basin (in the West) and in the Southern mountainous region. In the case of OKxyz, the distribution of the errors was remarkably regular throughout the region, and large errors were recorded only in the Southern ranges, over $1400 \mathrm{~m}$ above sea level. However, they comprised a very small area. They reached very high values because of the high semivariance values reached in the $Z$ variogram.

Table 4 shows the mean error and mean absolute error for the kriging and the regression models considering every prediction point, as well as the kriging standard error for the kriging models. The OK showed higher mean kriging standard error than the multivariate spatial models, and the latter showed poorer results than OKxyz, at every turn. The UK2 presented the highest mean kriging standard error among the multivariate models, although the low value of its NRMSE (Table 3) indicates that $\sigma_{\mathrm{UK}}\left(u_{a}\right)$ may overestimate the true error for UK2.

High altitude prediction is of great interest, as Asturias encompasses a large area at high elevations and as this prediction involves much complexity and difficulty. In Table 4 errors are also studied separately at low and high elevation ( $<600$ and $\geq 600 \mathrm{~m}$ above sea level). The range of MAE was below $1{ }^{\circ} \mathrm{C}$ in every technique which considered the elevation data. However, the ME indicated that the OKED had a larger bias than the UK1 and the UK2 at high elevations. The model R1 showed generally poorer results than the geostatistical models in terms of ME and MAE, meanwhile the R2 model showed the lowest MAE, both for high and low elevations and January and August temperatures.

Table 5 shows the results of the independent validation. As high altitude and low sampled areas
Table 4

Mean errors, mean absolute errors and mean kriging error resulting of the cross-validation for the geostatistical methods (OK: ordinary kriging; OKxyz: ordinary kriging in 3D; OKED: ordinary kriging with external drift, UK: universal kriging) and mean errors and mean absolute errors for regression models ( $\mathrm{R} 1$ is the model developed by Sánchez-Palomares et al. (1999) and R2 is the model developed by Ninyerola et al. (2005)) for all the sampled locations, and separately for those located over and below $600 \mathrm{~m}$ above sea level, in January and August

\begin{tabular}{|c|c|c|c|}
\hline & $\begin{array}{l}\text { Mean } \\
\text { error } \\
\left({ }^{\circ} \mathrm{C}\right)\end{array}$ & $\begin{array}{l}\text { Mean } \\
\text { absolute } \\
\text { error }\left({ }^{\circ} \mathrm{C}\right)\end{array}$ & $\begin{array}{l}\text { Kriging } \\
\text { standard } \\
\text { error }\left({ }^{\circ} \mathrm{C}\right)\end{array}$ \\
\hline \multicolumn{4}{|l|}{ All stations } \\
\hline OK January & 0.052 & 0.731 & 1.158 \\
\hline OKxyz January & 0.018 & 0.668 & 0.898 \\
\hline OKED January & 0.024 & 0.774 & 0.947 \\
\hline UK1 January & 0.020 & 0.791 & 0.958 \\
\hline UK2 January & 0.018 & 0.778 & 1.068 \\
\hline $\mathrm{R} 1$ & -0.087 & 0.796 & \\
\hline $\mathrm{R} 2$ & 0.070 & 0.377 & \\
\hline OK August & 0.029 & 0.788 & 0.742 \\
\hline OKxyz August & 0.009 & 0.567 & 0.664 \\
\hline OKED August & 0.032 & 0.624 & 0.59 \\
\hline UK1 August & 0.033 & 0.617 & 0.602 \\
\hline UK2 August & 0.032 & 0.608 & 0.701 \\
\hline $\mathrm{R} 1$ & 0.232 & 0.640 & \\
\hline $\mathrm{R} 2$ & -0.024 & 0.240 & \\
\hline \multicolumn{4}{|c|}{ Stations equal and over $600 \mathrm{~m}$} \\
\hline OK January & -0.386 & 0.788 & 1.227 \\
\hline OKxyz January & 0.100 & 0.678 & 0.995 \\
\hline OKED January & 0.094 & 0.841 & 0.966 \\
\hline UK1 January & 0.026 & 0.881 & 0.987 \\
\hline UK2 January & 0.006 & 0.846 & 1.105 \\
\hline $\mathrm{R} 1$ & -0.305 & 0.952 & \\
\hline $\mathrm{R} 2$ & -0.029 & 0.147 & \\
\hline OK August & -0.518 & 1.022 & 0.786 \\
\hline OKxyz August & -0.012 & 0.638 & 0.756 \\
\hline OKED August & -0.225 & 0.762 & 0.629 \\
\hline UK1 August & -0.111 & 0.734 & 0.654 \\
\hline UK2 August & -0.055 & 0.755 & 0.766 \\
\hline $\mathrm{R} 1$ & 0.025 & 0.552 & \\
\hline $\mathrm{R} 2$ & -0.096 & 0.152 & \\
\hline \multicolumn{4}{|c|}{ Stations below $600 \mathrm{~m}$} \\
\hline OK January & 0.251 & 0.706 & 1.098 \\
\hline OKxyz January & -0.019 & 0.664 & 0.814 \\
\hline OKED January & -0.007 & 0.744 & 0.931 \\
\hline UK1 January & 0.018 & 0.750 & 0.932 \\
\hline UK2 January & 0.023 & 0.747 & 1.036 \\
\hline $\mathrm{R} 1$ & 0.012 & 0.725 & \\
\hline $\mathrm{R} 2$ & 0.115 & 0.482 & \\
\hline OK August & 0.277 & 0.682 & 0.704 \\
\hline OKxyz August & 0.018 & 0.535 & 0.585 \\
\hline OKED August & 0.149 & 0.561 & 0.556 \\
\hline UK1 August & 0.098 & 0.565 & 0.558 \\
\hline UK2 August & 0.071 & 0.542 & 0.644 \\
\hline $\mathrm{R} 1$ & 0.326 & 0.680 & \\
\hline $\mathrm{R} 2$ & 0.009 & 0.280 & \\
\hline
\end{tabular}


Table 5

Mean temperature, mean errors (ME), mean absolute errors (MAE), kriging standard error estimates ( $\sigma$ ), normalised mean error (NME) and normalised root mean squared error (NRMSE) for the independent validation data set (OK: ordinary kriging; OKxyz: ordinary kriging in 3D; OKED: ordinary kriging with external drift, UK: universal kriging, R1 is the model developed by Sánchez-Palomares et al. (1999) and R2 is the model developed by Ninyerola et al. (2005)), in January and August

\begin{tabular}{|c|c|c|c|c|c|c|}
\hline & Temperature $\left({ }^{\circ} \mathrm{C}\right)$ & $\operatorname{ME}\left({ }^{\circ} \mathrm{C}\right)$ & $\operatorname{MAE}\left({ }^{\circ} \mathrm{C}\right)$ & $\sigma\left({ }^{\circ} \mathrm{C}\right)$ & NME & NRMSE \\
\hline \multicolumn{7}{|l|}{ January } \\
\hline $\mathrm{OK}$ & 6.3 & -0.373 & 1.049 & 1.277 & -0.276 & 1.283 \\
\hline OKxyz & 5.7 & 0.178 & 0.863 & 0.835 & 0.119 & 1.124 \\
\hline OKED & 5.8 & 0.120 & 0.866 & 0.953 & 0.104 & 1.116 \\
\hline UK1 & 5.8 & 0.107 & 0.862 & 0.959 & 0.064 & 1.119 \\
\hline $\mathrm{UK} 2$ & 5.8 & 0.074 & 0.856 & 1.076 & 0.183 & 1.118 \\
\hline $\mathrm{R} 1$ & 5.8 & 0.051 & 0.831 & & & \\
\hline $\mathrm{R} 2$ & 5.7 & 0.188 & 0.867 & & & \\
\hline \multicolumn{7}{|l|}{ August } \\
\hline $\mathrm{OK}$ & 18.6 & -0.348 & 1.041 & 0.830 & -0.460 & 1.857 \\
\hline OKxyz & 18.3 & -0.082 & 0.771 & 0.428 & -0.204 & 1.070 \\
\hline OKED & 18.5 & -0.244 & 0.897 & 0.649 & -0.456 & 1.218 \\
\hline UK1 & 18.4 & -0.213 & 0.888 & 0.652 & -0.413 & 1.215 \\
\hline UK2 & 18.4 & -0.197 & 0.884 & 0.768 & -0.335 & 1.198 \\
\hline $\mathrm{R} 1$ & 18.1 & 0.146 & 0.879 & & & \\
\hline $\mathrm{R} 2$ & 18.1 & 0.100 & 0.753 & & & \\
\hline
\end{tabular}

were relatively more frequent in the data set used for the independent validation, the mean estimated temperatures were lower than for the entire study area, and the errors and biases were higher than for the crossvalidation. However, the MAE was smaller than $1{ }^{\circ} \mathrm{C}$ for all the interpolation techniques except for OK. The $\mathrm{R} 1$ regression model showed smaller bias and MAE in January than the other techniques, whereas the OKxyz and R2 were the techniques which performed better in August. It was remarkable that the difference between the MAE made with R2 and the rest of techniques disappeared. Even in January, we can see that R2 presented poorer results that the geostatistical performances.

\section{Discussion}

Geostatistical techniques have been used to infer reasonable models, from accuracy and time-capacity computing points of view, of the mean air temperature in January and August. Air temperature is one of the main external factors affecting ecological processes. The three analysed geostatistical methods that included elevation as an auxiliary variable to estimate the distribution of mean monthly air temperature, showed similar patterns with reasonable estimation errors, as well as error estimations, which indicates the adequacy of the spatial models developed. Furthermore, a new approach based on $X Y Z$ kriging with zonal anisotropy in the $Z$ direction has been applied with promising results.
The absence of an underlying deterministic relationship between elevation and temperature constitutes the main difference between this approach and the multivariate geostatistical techniques and the regression models analysed.

August predictions had generally smaller errors than in January. This is in accordance with the higher variability in January data and the higher variances found in January variograms. This is similar to the trend found by Rolland (2002), where the air temperature interpolation error was higher in January than in July (the warmest month in its study region). As previously reported (Hudson and Wackernagel, 1994; Dodson and Marks, 1997), correlations between temperature and elevation may change seasonally, and were higher in this study in January than in August. A similar trend appeared in Israel (Kurtzman and Kadmon, 1999) where the regression coefficient between the January mean daily temperature and altitude reached $R^{2}=0.84$, meanwhile with June temperatures this coefficient was $R^{2}=0.57$. Besides, in Scotland (Hudson and Wackernagel, 1994), mean temperature of July held the weakest correlation coefficient with elevation of every studied month (January, April, July and October), because of the strong correlation with latitude in summer.

Taking into account these correlation coefficients, it is not surprising that the models inferred with the elevation data brought about more accurate predictions, because altitude plays a major part in climatic spatial 
(1)

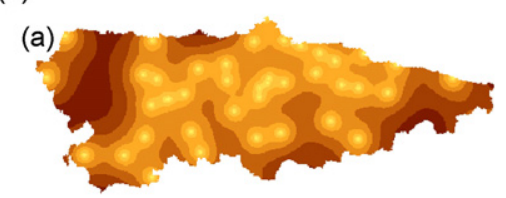

(b)

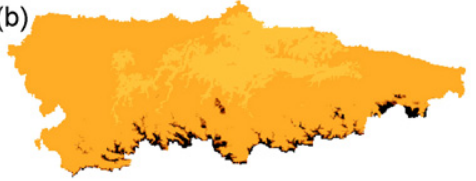

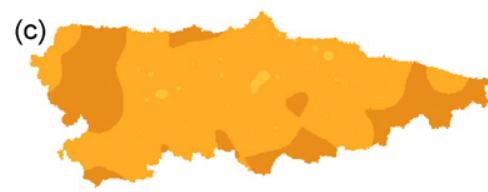

(2)

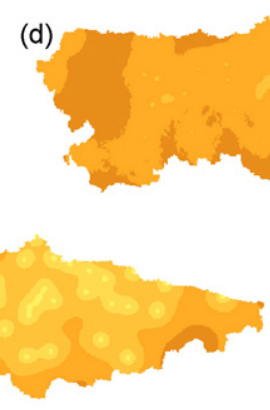

(b)

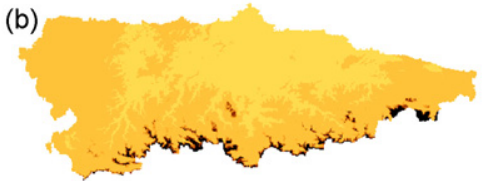

(a) (c)

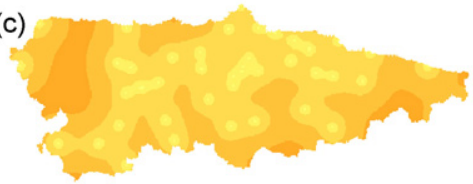

(d)
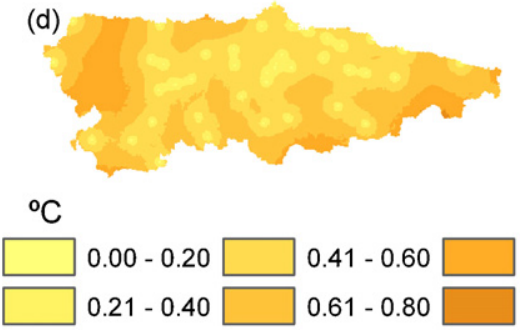

(e)
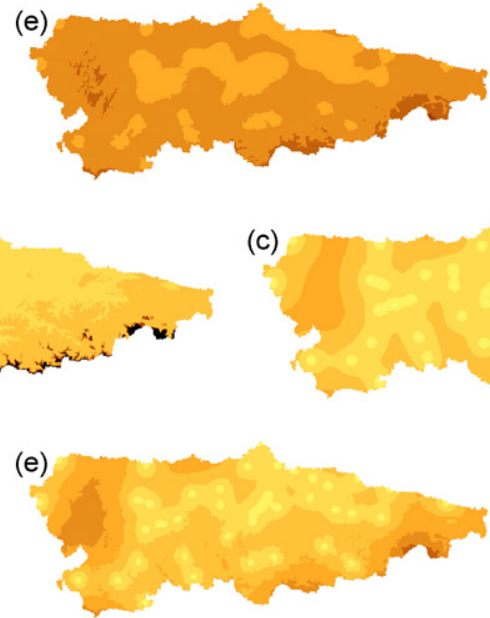

Fig. 6. Maps of the kriging (prediction) standard errors: (1) January, (2) August. (a) Ordinary kriging, (b) ordinary kriging in 3D, (c) ordinary kriging with external drift, (d) universal kriging 1, (e) universal kriging 2.

changes in mountainous areas (Stoutjesdijk and Barkman, 1992). OKxyz, UKs and OKED improved the temperature estimations made with OK. In Fig. 6 and in Table 4, the kriging errors and mean errors at sampled locations decreased when elevation was considered (on average $15 \%$ in kriging error terms). This improvement was greater in winter time (January) at high elevations $(\geq 600 \mathrm{~m})$. Recall that January temperatures showed higher correlation with altitude data.

The impressive differences in the prediction maps and the prediction errors between the OK and OKxyz techniques show the importance of the variogram model in the kriging prediction. In fact, the only difference between both approaches was the variogram computing method. With OKxyz, the kriging weights were drastically reduced when the altitude difference increased. Surprisingly, the prediction maps derived through OKxyz were very similar to those derived from the OKED, UK1, UK2 and the regression models, which assumed a deterministic linear relationship between temperature and elevation. However, the highest point prediction errors were recorded with the seemingly more accurate geostatistical technique, the OKxyz, with figures around $5{ }^{\circ} \mathrm{C}$ in January, and nearly $3{ }^{\circ} \mathrm{C}$ in August. In Fig. 6 these large prediction errors encompassed a small area with only $6.7 \%$ (January) and $4.8 \%$ (August) of the surface exceeding the prediction error by $1{ }^{\circ} \mathrm{C}$. Moreover, they matched up with the highest elevations (over $1400 \mathrm{~m}$ ), due to the high altitude differences between the nearest stations.

UK2 showed larger kriging errors than the other multivariate kriging methods $\left(1.4{ }^{\circ} \mathrm{C}\right.$ for both months), which is in accordance with the highest variogram sill value (Table 1). Nevertheless, $\sigma_{\mathrm{UK}}\left(u_{a}\right)$ for UK2 may be a more reliable estimator of the true kriging variance, as the NRSME indicates. In fact, the variogram estimate based on the OLS residuals had larger bias than the estimate based on the GLS residuals (Cressie, 1993).

Conversely, although the OKED and the UK1 techniques were based on the residuals of the same regression model, the UK1 included the elevation of the prediction points and the sampled points in the kriging system. Hence, UK1 must give more precise predicted error estimates (as the NME and the NRMSE indicate) than OKED, which does not incorporate the uncertainty within the internal model. 
For stations at altitudes above $600 \mathrm{~m}$, the MAE with OK was similar to the MAE with OKED, UK1 and $\mathrm{UK} 2$, but the ME indicated that $\mathrm{OK}$ estimates were strongly biased towards higher temperatures (Tables 4 and 5), probably because of the non-homogeneous altitudinal distribution of the stations. The inclusion of the variability on the $Z$ direction in the OKxyz seemed to solve the bias problem, and this approach held the best results in terms of MAE in both months. For the high altitude stations, the UK2 showed a smaller bias, specially in January, when the correlation between elevation and temperature was higher. Conversely, the OKED showed larger bias (mean error) than the other multivariate kriging methods, towards lower temperatures in January, and specially towards higher temperatures in August, when the correlation between elevation and temperature is lower. In fact, for August, the absolute value of the coefficient in the regression model was quite low, so the regression may overestimate high altitude temperatures, whereas the ordinary kriging may smooth the residuals at these altitudes. In January, it seems to occur conversely. The biased August temperature estimations with OKED were also corroborated by the independent validation.

The regression model with elevation as a unique independent variable showed a strong bias towards low temperatures at low altitudes in August and towards high temperatures at high altitudes in January, smoothing the extreme temperature values. The decrease in efficiency of simple regression analysis for assessing temperature with elevation was also confirmed by Rolland (2002). The model developed by Ninyerola et al. (2005), which included other variables such as the distance to the sea or the curvature radius of the terrain, showed much better performance in bias terms and was the most precise in MAE terms, particularly at higher elevations where MAE was under $0.16{ }^{\circ} \mathrm{C}$ for both months. Nonetheless, the R2 model gave more biased estimations than OKxyz and UK2, and its implementation was more complex than the rest as it requires a solar radiance model and some GIS development to derive the independent variables. Surprisingly, the independent validation, that mainly reflects the model's performance in poorly sampled areas, did not show better results for the regression models than for the kriging techniques. In fact, all the techniques except OK gave similar figures in terms of MAE. When accounting for the bias, the UK2 and R1 techniques showed slightly better results in January, when the correlation between elevation and temperature was higher, whereas in August the OKxyz and R2 regression model gave the best results.

\section{Conclusions}

In spite of the scarce and irregularly distributed number of sampled data, the models derived from geostatistical techniques with elevation as an auxiliary variable were quite accurate, especially the ordinary kriging $X Y Z$ with zonal anisotropy in the $Z$ direction. The variogram fitting procedure of the OKxyz has been developed in the frame of this research, and with the same independent variables (UTM-coordinates and elevation data) improved the regression models. These techniques were satisfactory, since other predictive models had lower predictive power (OK and R1) or they mean a complex analysis such as $\mathrm{R} 2$, which required technical resources that are not always available, and more time and computing-capacity. Also, it has been shown that predictions with $\mathrm{R} 2$ in places elsewhere do not necessarily provide the best results. Future directions of this research include the use of other variables in the multivariate kriging methods, continuing the trend followed by regression techniques, and the use of geostatistical techniques to study the temporal variability of ecological variables, a key aspect for every natural resources management.

\section{Acknowledgements}

We want to thank Miguel Ángel Álvarez, Director of the Instituto de Recursos Naturales y Ordenación del Territorio (INDUROT), Asturias, for supplying the temperature data set. We are also grateful to Dr. Grant Douglas, Dr. Sonia Roig and Rocio Rosa for their valuable comments on the manuscript. The research was supported by a fellowship awarded to R. Benavides from the Ministry of Education and Science of Spain, in the context of project AGL2003-05342.

\section{References}

Ayalew, L., Reik, G., Busch, W., 2002. Characterizing weathered rock masses-a geostatistical approach. Int. J. Rock Mech. Min. Sci. 39, 105-114.

Barry, R.G., Chorley, R.J., 1987. Atmosphere, Weather and Climate, fifth ed. Methuen and Co., London, 459 pp.

Blennow, K., 1993. Frost in July in a coastal area of southern Sweden. Weather 48, 217-222.

Blennow, K., 1998. Modelling minimum air temperature in partially and clear felled forest. Agric. Forest Meteorol. 91, 223235.

Carrega, P., 1995. A method for reconstruction of mountain air temperatures with automatic cartographic applications. Theor. Appl. Climatol. 52, 69-84.

Cressie, N.A.C., 1993. Statistics for Spatial Data. Wiley, New York, 900 pp. 
De Iaco, S., Myers, D.E., Posa, D., 2002. Nonseparable space-time covariance models: some parametric families. Math. Geol. 34, 23-42.

De Phillips, A., 1951. Forest ecology and phytoclimatology (on line) Unasylva 5 (1), available in: http://www.fao.org/documents/ show_cdr.asp?url_file=/docrep/x5358e/x5358e03.htm (Consulted: March 2006).

del Valle, S., 2004. Determinación con base ecológica de la Productividad Potencial Forestal in la provincia de Santiago de Estero, Argentina (Determination of the potential forest productivity in the province of Santiago de Estero, Argentina, with ecological basis). Doctoral Thesis, Universidad Politécnica de Madrid.

Dodson, R., Marks, D., 1997. Daily air temperature interpolated at high spatial resolution over a large mountainous region. Climate Res. 8, 1-20.

Fliri, F., 1975. Das Klima der Alpen in Raume von Tirol, Monographien zur Landskunde Tirols (The climate of the Alps in the Tirol area. Monographics of Tirol geography). Folgen, Universität Wagner, Innsbruck, München, 454 pp.

Gafta, D., Pedrotti, F., 1996. Fitoclima del Trentino-Alto-Adige Südtirol studi Trentini di scienze naturali (Phitoclimate of the Trentino-Alto-South Tirol. Trentini studies of Natural Sciences). Acta Biol 73, 55-100.

Gandullo, J.M., 1994. Climatología y ciencias del suelo (Climatology and Soil Sciences). Fundación Conde del Valle Salazar, ETSI Montes, Madrid, 408 pp.

García, L., Reija, A., 1994. Tiempo y clima en España. Meteorología de las Comunidades Autónomas (Weather and climate in Spain: meteorology of the different autonomous communities). Dossat2000, Madrid, $410 \mathrm{pp}$.

Geisser, S., 1975. The predictive simple rause method with applications. J. Am. Stat. Assoc. 70, 320-328.

Goodale, C.L., Albert, J.D., Ollinger, S.V., 1998. Mapping monthly precipitation, temperature and solar radiation for Ireland with polynomial regression and digital elevation model. Climate Res. 10, 35-49.

Goovaerts, P., 1999. Geostatistics in soil science: state-of-the-art and perspectives. Geoderma 89, 1-45.

Gringarten, E., Deutsch, C.V., 2001. Variogram interpretation and modeling. Math. Geol. 33, 507-534.

Hägglund, B., 1981. Evaluation of forest site productivity. Forest Abstr. 42 (11), 515-527 (review article).

Hayhoe, H.N., Lapen, D.R., 2001. Spatially modelling temperature normals in the Rocky Mountains with kriging and cokriging estimators using ANN produced secondary information. In: Proceedings II Conference of Artificial Intelligence, AMS, Annual Meeting, Long Beach, CA.

Hudson, G., Wackernagel, H., 1994. Mapping temperature using kriging with external drift: theory and example from Scotland. Int. J. Climatol. 14, 77-91.

Isaaks, E.H., Srivastava, R.M., 1989. Applied Geostatistics. Oxford University Press, New York, 561 pp.

Ishida, T., Kawashima, S., 1993. Use of cokriging to estimate surface air temperature from elevation. Theor. Appl. Climatol. 47, 147157.

Kurtzman, D., Kadmon, R., 1999. Mapping of temperature variables in Israel: a comparison of different interpolation methods. Climate Res. 13, 33-43.

Lapen, D.R., Hayhoe, H.N., 2003. Spatial analysis of seasonal and annual temperature and precipitations normals in Southern Ontario, Canada. J. Great Lakes Res. 29 (4), 529-544.
Li, X., Cheng, G., Lu, L., 2005. Spatial analysis of air temperature in Qinghai-Tibet Plateau. Arctic Antarct. Alpine Res. 37 (2), 246252.

Lutgens, F.K., Tarbuck, E.J., 1995. The Atmosphere: An Introduction to Meteorology, sixth ed. Prentice-Hall, Englewood Cliffs, NJ, $462 \mathrm{pp}$.

Marquínez, J., Lastra, J., García, P., 2003. Estimation models for precipitation in mountainous regions: the use of GIS and multivariate analysis. J. Hydrol. 270, 1-11.

Montes, F., Hernández, M.J., Cañellas, I., 2005. A geostatistical approach to cork production sampling estimation in Quercus suber forests. Can. J. Forest Res. 35, 2787-2796.

Myers, D.E., Journel, A., 1990. Variograms with zonal anisotropies and non-invertible kriging systems. Math. Geol. 22, 779-785.

Nalder, I.A., Ross, W.W., 1998. Spatial interpolation of climatic normals: test of a new method in Canadian boreal forest. Agric. Forest Meteorol. 92, 211-225.

Neuman, S.P., Jacobson, E.A., 1984. Analysis of nonintrinsic spatial variability by residual kriging with application to regional groundwater levels. J. Int. Assoc. Math. Geol. 16, 499-521.

Ninyerola, M., Pons, X., Roure, J.M., 2000. A methodological approach of climatological modelling of air temperature and precipitation through GIS techniques. Int. J. Climatol. 20, 1823-1841.

Ninyerola, M., Pons, X., Roure, J.M., 2005. Atlas climático digital de la Península Ibérica. Metodología y Aplicaciones en bioclimatología y geobotánica (Digital Climatic Atlas of the Iberian Peninsula. Methodology and Implementations in Bioclimatology and Geobotanic) (on line) ISBN 932860-8-7. Universidad Autónoma of Barcelona. Besllaterra. Available in: http://opengis.uab.es/wms/ iberia/mms/index.htm (Consulted: April 2006).

Richardson, A.D., Lee, X., Friedland, A.J., 2004. Microclimatology of treeline spruce-fir forests in mountains of the northeastern United States. Agric. Forest Meteorol. 125, 53-66.

Robeson, S.M., 1994. Influence of spatial interpolation and sampling on estimates of terrestrial air temperature change. Climate Res. 4 (2), 119-126.

Rolland, C., 2002. Spatial and seasonal variations of air temperature lapse rate in Alpine region. J. Climate (Am. Meteorol. Soc.) 16 (7), 1032-1046.

Rouhani, S., Myers, D.E., 1990. Problems in space-time kriging of geohydrological data. Math. Geol. 22, 611-623.

Rubio, A., Sánchez, O., Gómez, V., Graña, D., Elena, R., Blanco, A., 2002. Autoecología de los castañares de Castilla (España) (Autoecology of chestnut tree forest in Castilla, Spain). Investigación Agraria: Sistemas de Recursos Forestales 11 (2), 373-393.

SADEI (Sociedad Asturiana de Estudios Económicos e Industriales), 2005. Superficie de Asturias según estratos de pendiente (Surface area of Asturias according to slopes ranges). Based on the National Geographic Institute's Source (on line), available in: http://www.sadei.es/datos/cuadros\%20tematicos/capitulo\%20A/ 4/A40004XXXXXa.xls (Consulted: August 2006).

Sánchez-Palomares, O., Sánchez-Serrano, F., Carretero, M. P., 1999. Modelos y Cartografía de estimaciones climáticas termopluviométricas para la España peninsular (Models and Maps of the climatic variables estimates in peninsular Spain). Ministerio de Agricultura, Pesca y Alimentación. Instituto Nacional de Investigación y Tecnología Agraria y Alimentaria, Madrid, 192 pp.

Sánchez-Palomares, O., Rubio, A., Blanco, A., Elena, R., Gómez, V., 2003. Autoecología paramétrica de los hayedos de Castilla y León (Parametric Autoecology of beech tree forest in Castilla y León). Investigación Agraria: Sistemas de Recursos Forestales 12 (1), $87-110$. 
Serrada, R., 1976. Método para la evaluación con base ecológica de la productividad potencial de las masas forestales en grandes regiones y su aplicación a la España Peninsular (Methodology for assessing the potential productivity of forest in large regions and its application in peninsular Spain). Doctoral Thesis, Universidad Politécnica of Madrid.
Stone, M., 1974. Cross-validation choice and assessment of statistical predictions. J. Royal Stat. Soc. B 36, 111-133.

Stoutjesdijk, P., Barkman, J.J., 1992. Microclimate, Vegetation and Fauna. Opulus Press, Sweden, 216 pp.

Thom, H.C.S., 1966. Some Methods of Climatology Analysis. W.O.M., 415, Technical Report 81, Gèneve. 